Section Editor

Mitchell S.V. Elkind,

MD, MS

\title{
Ocular motor abnormalities in bilateral paramedian thalamic stroke
}

\section{PEARLS}

- The thalamus is supplied by 4 bilateral arterial systems: 3 derived from the vertebrobasilar system and 1 derived from the posterior communicating artery (PCA), each supplying the ipsilateral thalamus.

- Top of the basilar syndrome caused by occlusion of the rostral portion of the basilar artery can present with an array of visual, oculomotor, and behavioral abnormalities as a result of ischemia to midbrain, thalami, and temporal and occipital lobes.

\section{OY-STERS}

Dr. Gooneratne:

kishig@gmail.com

- The artery of Percheron (AOP) is an anatomical variant arising from a single PCA and supplies the bilateral medial thalamus.

- Bilateral paramedian thalamic strokes due to AOP occlusion are characterized by altered mental status, vertical gaze palsy, and memory impairment, and are similar in presentation to top of the basilar syndrome. The absence of posterior cortical visual disturbances favors AOP occlusion.

CASE 1 A 67-year-old right-handed man with hypertension was admitted to a rural hospital with sudden onset of confusion, double vision, and bilateral drooping of the eyelids. He had difficulty walking and altered behavior. He was afebrile and rest of his clinical examination had normal results. $\mathrm{He}$ was admitted to the intensive care unit and managed as a suspected krait bite (due to its high prevalence in the area), although there was no history of a snakebite. Forty-eight hours later, the patient was fully oriented. His eye signs were persistent and he was referred to our institution for further evaluation.

Neurologic examination of the eyes (figure 1) revealed bilateral asymmetric ptosis and skew eye deviation (vertical misalignment of the eyes where the eyes move upward, but in opposite directions) with an exotropia (divergent squint). Adduction of the eyes was impaired bilaterally. There was no nystagmus. Vertical saccadic and pursuit eye movements were minimal. On oculocephalic maneuvers, the eye movements were restored. Pupillary examination, convergence, and the rest of the cranial nerves were normal. The rest of the cerebellar, motor, and sensory systems were normal.

His brain MRI, which was done 1 week after the onset of symptoms, revealed bilateral thalamic $\mathrm{T} 1$ low signal intensities and T2 high signal intensities with minimal gadolinium enhancement suggestive of bilateral thalamic infarctions. Diffusion-weighted imaging demonstrated restricted diffusion in the same region. There was no concurrent midbrain lesion. Magnetic resonance angiogram and venogram had normal results. A diagnosis of bilateral thalamic infarction due to occlusion of the AOP was made. A source of cardiothromboembolism was not elicited. The patient was managed with antiplatelets. Lid crutches were prescribed for his ptosis.

CASE 2 A 47-year-old woman presented with 3 days history of acute onset of dizziness, transient loss of consciousness, and binocular diplopia with difficulty in walking unassisted. She was confused and amnesic after she regained consciousness in the hospital. Her clouded consciousness improved in a few days. A history of hypertension and diabetes mellitus for 2 years was also elicited. Examination of the eyes (figure 2) revealed an exotropia. Adduction of the eyes was significantly impaired bilaterally, which was accompanied by conjugate downgaze palsy, which was corrected by ocular-cephalic maneuvers. Pupillary reflexes and convergence were intact. The rest of the examination had normal results.

MRI brain showed T1 hypointense and T2/fluidattenuated inversion recovery (FLAIR) hyperintense lesions in the paramedian thalamus bilaterally, which also showed diffusion restriction. Magnetic resonance angiogram with venogram had normal results. Biochemistry, lipid profile, and blood counts were normal. A diagnosis of bilateral thalamic infarction due to occlusion of the AOP was made. The patient was started on antiplatelet medication and her 


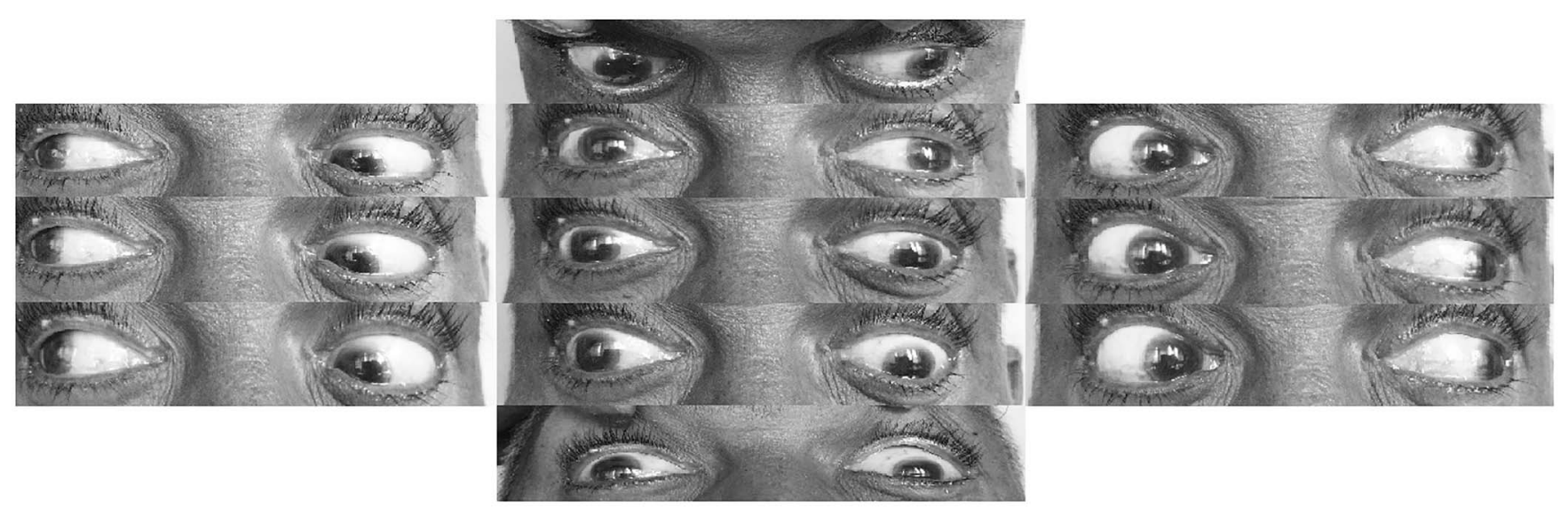

Patient 1 with supranuclear gaze palsy and bilateral internuclear ophthalmoplegia.

diabetes and hypertension were optimized. Her eye findings did not resolve on discharge.

CASE 3 A 42-year-old woman with an unremarkable medical history was admitted with sudden onset of loss of consciousness. She regained consciousness after 24 hours and thereafter remained drowsy for 1 week. On examination after regaining consciousness, she was drowsy and disoriented in time and place. Neurologic examination showed vertical gaze palsy, which was corrected by ocular-cephalic maneuvers (figure 3). Horizontal eye movements were normal. The rest of the neurology examination had normal results, including pupils and convergence.

MRI brain showed abnormal signal intensities in bilateral thalami, which were hypointense in $\mathrm{T} 1$ and hyperintense with T2/FLAIR sequence with minimal contrast enhancement. There was evidence of diffusion restriction on diffusion-weighted imaging (figure 4). Four-vessel digital subtraction angiography of the cerebral circulation was normal. Basic biochemistry, infective, vasculitic, and thrombophilic screen had normal results. Echocardiography did not reveal any source of cardioembolism. Cryptogenic stroke due to occlusion of the AOP was diagnosed and antiplatelet medication was initiated. The patient made a gradual recovery with normal level of consciousness prior to discharge from the hospital. Her ocular palsy remains 3 months following her stroke.

DISCUSSION The thalamus is supplied by 4 arterial systems: 3 derived from the vertebrobasilar system (paramedian thalamo-subthalamic, inferolateral thalamogeniculate, and posterior choroidal arteries) and 1 derived from the posterior communicating artery (polar artery). Vascular lesions in each of these territories give rise to a range of distinct clinical syndromes. ${ }^{1}$ The AOP, an anatomical variant, is a single dominant thalamo-perforating artery (present in $4 \%-12 \%$ of the population) that arises from a single PCA and supplies the bilateral medial thalamus with variable contribution to the rostral midbrain. ${ }^{2}$

Bilateral paramedian midbrain-thalamic infarction as a result of occlusion of the AOP usually produces

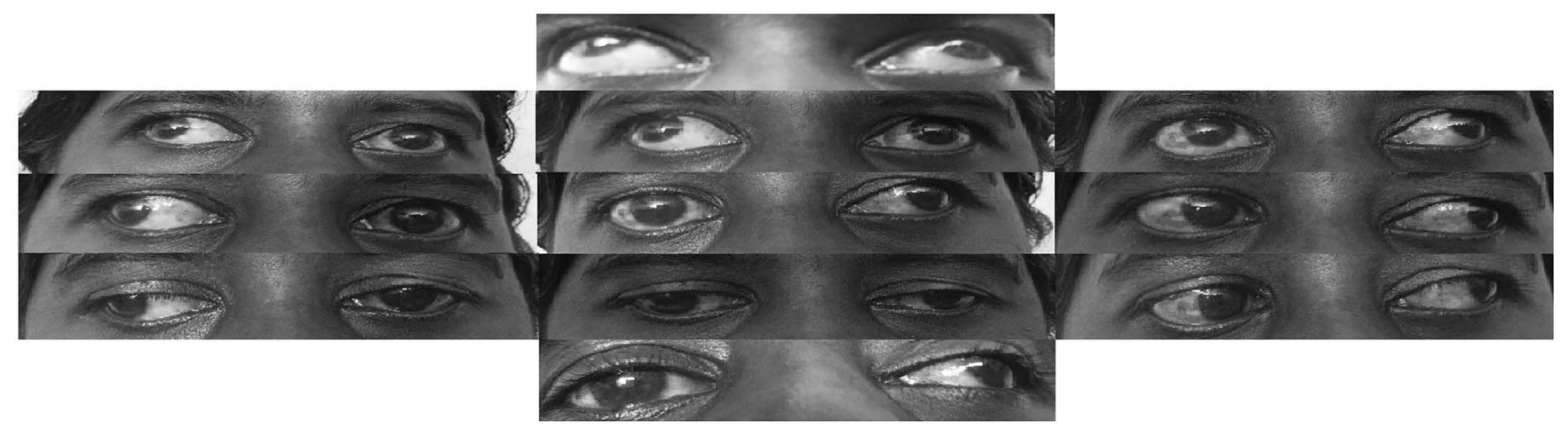

Patient 2 with supranuclear gaze palsy and bilateral internuclear ophthalmoplegia. 


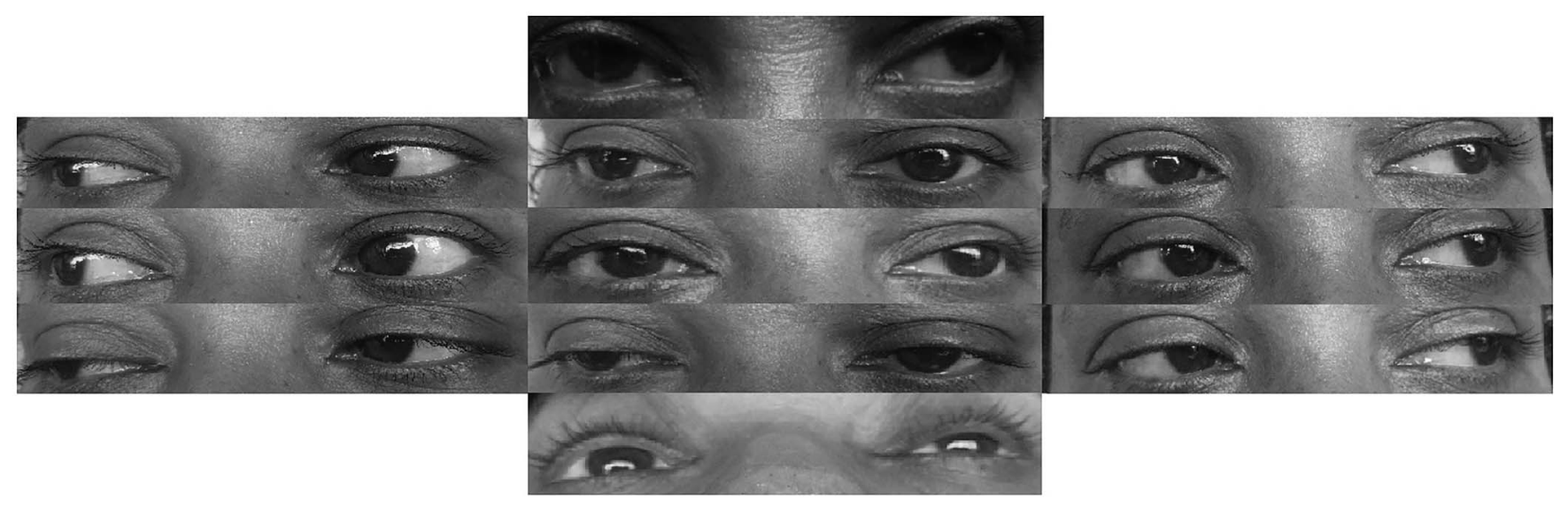

Patient 3 with supranuclear gaze palsy.

alterations in level of consciousness, cognitive deficits, behavioral problems, and distinctive ocular motor abnormalities. ${ }^{3-5}$ These ocular abnormalities include third nerve palsy, vertical gaze palsy, loss of convergence, pseudo-sixth nerve palsies, miosis, intolerance to bright light, and bilateral internuclear ophthalmoplegia. ${ }^{5}$ The most prominent clinical finding in these 3 patients was vertical gaze palsy, which was of supranuclear origin. This finding is the commonest ophthalmologic finding in this kind of stroke. ${ }^{6}$ Two out of 3 had coexistent impaired horizontal gaze, with both demonstrating bilateral internuclear ophthalmoplegia
(INO). Moreover, there was no MRI evidence of significant ischemia of midbrain or thalamo-midbrain junction in the 3 patients.

Control of vertical gaze is not well-understood. However, according to the current understanding, neural structures involved in vertical gaze lie in the midbrain reticular formation. These include the nucleus of Darkschewitsch (evidence for its function not as robust), the interstitial nucleus of Cajal, and the posterior commissure. ${ }^{6}$ Vertical gaze depends also on input from fiber pathways that ascend from the vestibular system through the medial longitudinal

Figure $4 \quad$ Imaging of the patients

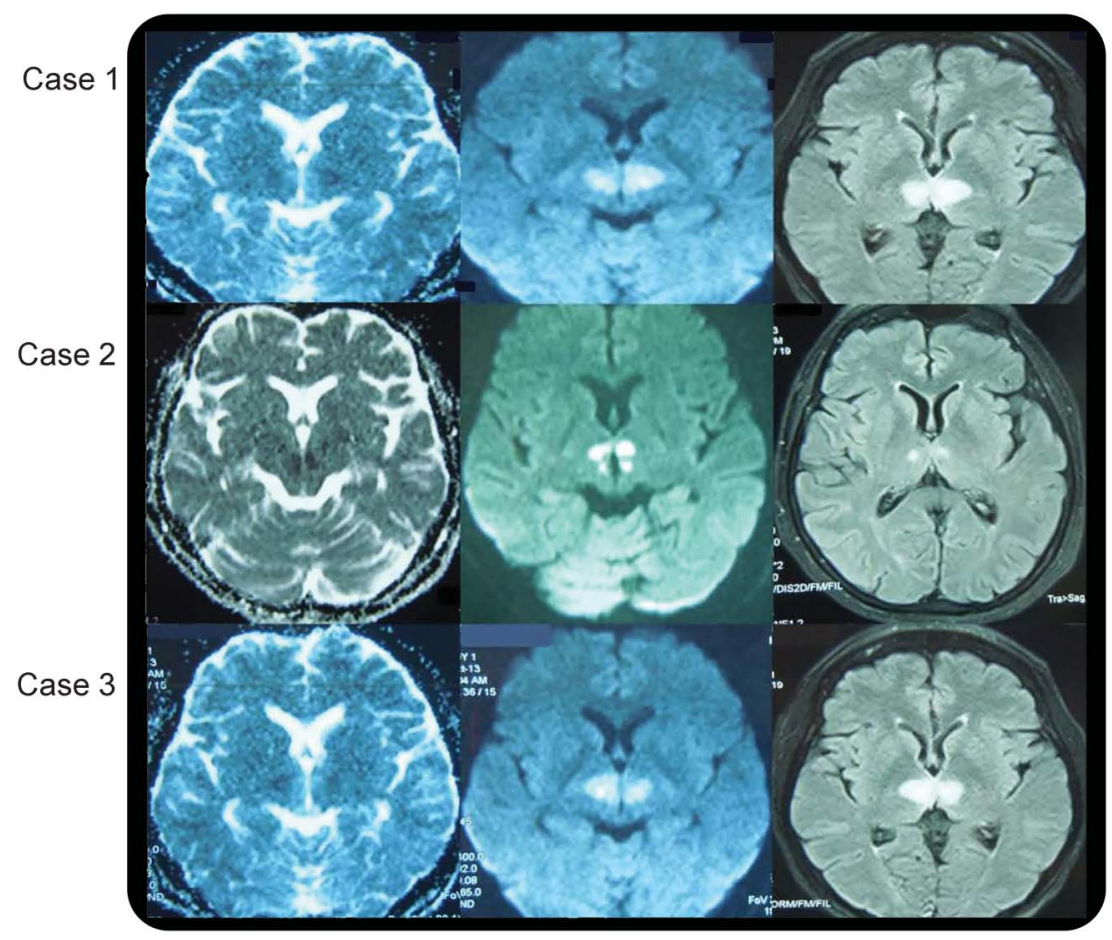

MRI brain (diffusion-weighted imaging/fluid-attenuated inversion recovery) shows bilateral paramedian thalamic infarction (similar in all 3 patients) 
fasciculus (MLF). Therefore, the rostral interstitial nucleus of the MLF (riMLF), which integrates the neural input into a final command for vertical gaze, is an integral part of vertical saccadic movement. Thus lesions affecting any of these structures give rise to impaired vertical gaze. It was unusual to note that none of these midbrain structures seemed to be involved in imaging in the above case series. This suggests 2 possibilities: lesions in the midbrain were too small to be detected due to the thickness of the MRI slices ( $5 \mathrm{~mm}$ per slice) or the thalamic lesions alone may have produced vertical gaze palsy by interrupting supranuclear inputs. Previous case series have reported similar clinicoradiologic findings, which may suggest plausibility of the latter postulation. These reported thalamic lesions were characterized by disturbances of horizontal and vertical gaze separately. ${ }^{6,7}$ Damage to the adjacent riMLF or its immediate premotor inputs was postulated as the probable mechanism in these cases. Two out of 3 patients in our series also exhibited deficiencies in horizontal gaze (i.e., bilateral INO). Only a few case series have described bilateral INO previously. ${ }^{5}$ In the presence of bilateral INO with radiologically uninvolved brainstem, possibility of involvement of MLF fibers has to be considered. This could be supported by the fact that AOP has a variable supply to rostral midbrain. Moreover, combined vertical gaze palsy and bilateral INO have been poorly described in the literature. The first patient also exhibited bilateral ptosis, which was asymmetrical, added to the vertical gaze palsy and bilateral INO, which may represent bilateral 3rd nerve palsy. However, preservation of the ocular-cephalic reflex suggested that the manifestations were of supranuclear origin. Complete ophthalmoplegia in bilateral paramedian thalamic infarction has been reported. ${ }^{8}$ However, there was significant concurrent midbrain involvement, in contrast to our series. The third case was of a typical supranuclear gaze palsy, which is the commonest manifestation in this type of stroke.

Top of the basilar syndrome, an important differential diagnosis, can present similarly with an array of visual, oculomotor, and behavioral abnormalities. ${ }^{9}$ It is caused by occlusion of the rostral portion of the basilar artery. Thus typically infarcts of not only the bilateral thalami but the posterior cerebral, superior cerebellar artery, and pontine vascular territories are seen. This can result in neurologic deficits of the midbrain and thalami, as well as of the temporal and occipital lobes. Differentiation between a top of the basilar syndrome and AOP occlusion clinically is challenging; however, the presence of posterior cortical visual disturbance such as hemianopia, visual perseverations, cortical blindness, and Balint syndrome favor the former. ${ }^{9}$

A typical MRI of an AOP occlusion shows bilateral thalamus infarction with or without midbrain involvement with good patency of the vertebrobasilar system. Conventional angiography and angio-MRI are of little value in validating the occlusion of the AOP because this is a small-caliber vessel, difficult to be visualized radiologically even when anatomically intact. ${ }^{10}$ Visualization of a fully patent basilar artery makes the diagnosis of top of the basilar artery syndrome very unlikely, making occlusion of the AOP the more likely diagnosis considering the pattern of infarction with the absence of posterior cortical involvement. ${ }^{10}$

This case series highlights the fact that occlusion of the AOP may give rise to a range of complex ocular motor defects due to possible disruption of supranuclear inputs from the thalamus or thalamo-midbrain junction. This could be confirmed by further autopsy studies. Advances in neural network imaging could conceivably be able to delineate the deficit in anatomy without using autopsies.

\section{AUTHOR CONTRIBUTIONS}

I.K.G., M.C.C., D.S.L., L.P., K.V., and R.G. were involved in the management of the patients and preparation of the manuscript for submission.

\section{STUDY FUNDING}

No targeted funding reported.

\section{DISCLOSURE}

The authors report no disclosures relevant to the manuscript. Go to Neurology.org for full disclosures.

\section{REFERENCES}

1. Schmahmann JD. Vascular syndromes of the thalamus. Stroke 2003;34:2264-2278.

2. Cao W, Dong Q, Li L, Dong Y. Bilateral thalamic infarction and DSA demonstrated AOP after thrombosis. Acta Radiol Short Rep 2012;1:5.

3. Kumral E, Evyapan D, Kutluhan S. Pure thalamic infarctions: clinical findings. J Stroke Cerebrovasc Dis 2000;9: 287-297.

4. Castaigne P, Lhermitte F, Buge A, Escourolle R, Hauw JJ, Lyon-Caen O. Paramedian thalamic and midbrain infarcts: clinical and neuropathological study. Ann Neurol 1981;10:127-148.

5. Bogousslavsky J, Regli F, Uske A. Thalamic infarcts: clinical syndromes, etiology, and prognosis. Neurology 1988; 38:837-848.

6. Clark JM, Albers GW. Vertical gaze palsies from medial thalamic infarctions without midbrain involvement. Stroke 1995;26:1467-1470.

7. Genc E, Dogan EA, Akca AA, İlhan S. Two cases of vertical gaze palsy: one with and the other without midbrain involvement. Türk Serebrovasküler Hastalıklar Dergisi 2007;3:97-100.

8. Thurtell MJ, Halmagyi GM. Complete ophthalmoplegia an unusual sign of bilateral paramedian midbrain-thalamic infarction. Stroke 2008;39:1355-1357.

9. Caplan LR. Top of the basilar syndrome. Neurology 1980; 30:72.

10. Alaicescu M, Nistorescu A, Popa G, et al. Anatomic, clinical and pathophysiologic correlates in acute bilateral paramedian thalamic infarcts. Revista Romana Neurologie 2007;6:88-91. 


\section{Neurology}

\section{Pearls \& Oy-sters: Ocular motor abnormalities in bilateral paramedian thalamic stroke}

Inuka Kishara Gooneratne, Manjula Chandragomi Caldera, Damith Sanjaya Liyanage, et al. Neurology 2015;84;e155-e158

DOI 10.1212/WNL.0000000000001579

\section{This information is current as of May 18, 2015}

\section{Updated Information \&} Services

References

Subspecialty Collections

Permissions \& Licensing

Reprints including high resolution figures, can be found at: http://n.neurology.org/content/84/20/e155.full

This article cites 10 articles, 5 of which you can access for free at: http://n.neurology.org/content/84/20/e155.full\#ref-list-1

This article, along with others on similar topics, appears in the following collection(s):

\section{Infarction}

http://n.neurology.org/cgi/collection/infarction

Ocular motility

http://n.neurology.org/cgi/collection/ocular_motility

Stroke in young adults

http://n.neurology.org/cgi/collection/stroke_in_young_adults

Information about reproducing this article in parts (figures,tables) or in its entirety can be found online at:

http://www.neurology.org/about/about_the_journal\#permissions

Information about ordering reprints can be found online:

http://n.neurology.org/subscribers/advertise

Neurology ${ }^{\circledR}$ is the official journal of the American Academy of Neurology. Published continuously since 1951, it is now a weekly with 48 issues per year. Copyright () 2015 American Academy of Neurology. All rights reserved. Print ISSN: 0028-3878. Online ISSN: 1526-632X.

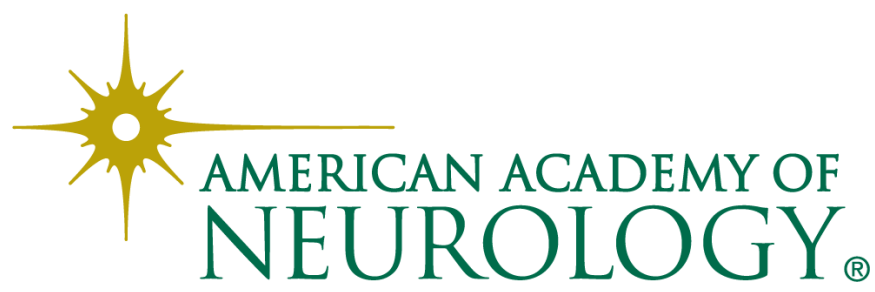

